\title{
Etnografía de las elecciones seccionales de 2019 en el Ecuador. Una mirada antropológica sobre la cultura política ecuatoriana el día de la votación.
}

\section{Ethnograpy of the 2019 sectional elections in Ecuador. An anthropological view of the Ecuadorian political culture on the voting day.}

\section{Andrea Madrid Tamayo}

Recepción: 1 de septiembre de 2019 Aprobación: 6 de noviembre de 2019

\section{Resumen}

E1 24 de marzo de 2019 en Ecuador se eligieron 11.069 autoridades locales y miembros del Consejo de Participación Ciudadana y Control Social. El proceso de votación permitió evidenciar rasgos de la cultura política ecuatoriana, las complejidades sociales que la envuelven, cómo se percibió la democracia y el acto de votar por parte de la población, etc. En este contexto, se realizó un análisis etnográfico en tres recintos electorales del sur de Quito, buscando responder: ¿Es posible que a través de la comprensión de los procesos sociales y culturales que se generan durante la votación, se pueda contribuir a evidenciar elementos que caractericen el proceso electoral? Desde allí se ha dado lugar a una reflexión metodológica y epistemológica sobre el uso de la etnografía en el análisis de "lo político".

Palabras claves: etnografía, proceso electoral, percepción, democracia

\section{Abstract}

On March 24, 2019 in Ecuador, 11,069 local authorities were elected, including members of the Council for Citizen Participation and Social Control. The voting process allowed showing features of the Ecuadorian political culture, the social complexities that surround it, how democracy and the act of voting by the population were perceived, etc. In this context, an ethnographic analysis was carried out in three polling stations in the south of Quito seeking to answer: Is it possible that through the understanding of the social and cultural processes that are generated during the votinglife, to contribute to exhibit elements that characterize the electoral process? From there, there has been made a methodological and epistemological reflection on the usage of ethnography in the analysis of "the political."

Keywords: ethnography, electoral process, perception, democracy 


\section{Introducción}

n Ecuador, cada dos años ${ }^{1}$, durante el día de las elecciones, es posible observar como la cotidianidad de la población se transforma durante el proceso electoral, una de las principales manifestaciones de la democracia representativa. Esta vivencia ciudadana, que se presenta elección tras elección, da cuenta de una cultura política compleja que ha sido poco analizada (Tocancipá 1998: 2).

En este contexto, el objetivo de este artículo es doble. Por un lado, presentar los resultados de investigación en torno a los comportamientos que se van volviendo cotidianos durante el día de las votaciones: las actividades que se realizan, las percepciones de la población, la apropiación del espacio público para cargarlo de significado y en general los elementos socioculturales que forman parte del proceso electoral en Ecuador. Por otro, es importante generar una reflexión epistemológica y metodológica sobre la etnografía y su uso en la ciencia política y en los fenómenos vinculados con el análisis de "lo político".

El voto es una expresión del sistema político, una acción a través de la cual el/la votante emite su opinión política en el contexto electoral; sin embargo, en este ejercicio también se involucra su entorno social (Tocancipá, 2000: 1). Este influye directamente en su percepción sobre la democracia, en la forma de entender y vivir el sistema democrático de un determinado país e incluso en sus decisiones sobre el proceso electoral. Si bien la democracia no se puede reducir a las elecciones, el proceso electoral es un elemento constitutivo y fundamental de la democracia representativa (PNUD 2004: 26).

El acto de votar es un fenómeno que se repite cada cierto tiempo en el contexto político de cada país, pero que además da cuenta de prácticas

\footnotetext{
1.- En Ecuador, "las elecciones se realizarán cada cuatro años para elegir presidente y vicepresidente, miembros de la Asamblea Nacional y representantes al Parlamento Andino" (Código de la Democracia, 2009: Art. 89). "Las elecciones de gobernadores/as regionales, consejeros/as regionales, prefectos/as, alcaldes/as y vocales de juntas parroquiales rurales se realizan de la misma manera cada cuatro años (Código de la Democracia, 2009: Art. 90). Ambas elecciones, nacionales y locales, no serán concurrentes y se alternarán (CRE, 2008: Régimen de transición Art. 9).
} 
culturales particulares que son propias de cada pueblo, y que sugieren formas variadas de percibir la participación en relación con el voto (Tocancipá 2000: 1). En este sentido, la pregunta de investigación reflexiona en torno a si a través de la comprensión de los procesos sociales y culturales, que se generan durante la votación (en la esfera de lo político, lo económico y la vida cotidiana), se puede contribuir a evidenciar elementos que caractericen el proceso electoral ecuatoriano, así como sobre la utilidad de la metodología etnográfica para analizar fenómenos de carácter político.

Las diferentes formas a través de las cuales la población participa y se expresa el día de las elecciones generan una conexión entre la cultura y la política, que impacta directamente en la institucionalidad estatal, dejan huella en la memoria ciudadana, cambian la percepción del entorno, consolidan una imagen del urbano cotidiano y le dan un sentido particular al proceso democrático y a la forma de vivir la democracia. Por ello, se vuelve importante analizar las acciones colectivas y los mecanismos a través de los cuales la gente se apropia y le otorga significados socio-culturales al proceso de votación.

Alrededor de esto surgen múltiples preguntas: ¿Qué pasa en el recinto electoral, qué actitud tiene la gente? ¿Quiénes van al recinto electoral? ¿De qué habla la gente el día de las elecciones? ¿Cómo es el flujo electoral en los recintos? ¿Qué interacciones sociales se producen? ¿Cuál es el impacto de estas acciones cotidianas en las estructuras macro sociales? ¿Qué redes de significados se tejen alrededor de esto? ¿Cuáles son los discursos que asumen los actores implicados? ¿Cuáles son las prácticas y los comportamientos de la gente? ¿Cómo se viven en este contexto los procesos de construcción identitaria y de re-significación de los espacios?, etc.

Para encontrar las respuestas, el presente estudio se realizó mediante un análisis etnográfico en tres recintos electorales: 1) el Colegio María Augusta Urrutia (MAUE), 2) la Escuela Eduardo Vásquez Dodero y 3) la Unidad Educativa Consejo Provincial de Pichincha; pertenecientes a la parroquia de Solanda localizada al sur de Quito, un sector de estrato social medio-bajo. El registro electoral de la Zona de Solanda, a diferencia del censo poblacional que registra 78.279 habitantes (INEC 2010), está compuesto por 44.462 electores 
y electoras (personas de 16 años y más que están facultadas por la ley para ejercer su derecho al sufragio) (Fuente: Coordinación Nacional Técnica de Procesos Electorales - Dirección Nacional de Registro Electoral - CNE 2019).

La división de Quito por barrios responde a un contexto social y cultural. No obstante, para efectos censales-electorales, el Consejo Nacional Electoral utiliza una división que se fundamenta en Circunscripciones Electorales (que en el caso de la provincia de Pichincha y del cantón Quito corresponden a tres: norte, centro y sur). El barrio de Solanda forma parte de la Circunscripción urbana Nro. 3 - Sur, el cual está constituida por 10 parroquias: Chillogallo, Guamaní, La Argelia, La Mena, La Ecuatoriana, Quitumbe, Turubamba, San Bartolo, La ferroviaria y Solanda. Dentro de la parroquia Solanda se localizan 4 zonas electorales, en el centro de las cuales está el Sector 4, que coincide con el barrio de nuestro análisis, al interior del cual se localizan los recintos electorales, que contienen a las juntas receptoras del voto.

A través de la etnografía se pretende registrar la variedad de situaciones e interacciones que evidencian la complejidad de la cultura política en la vida cotidiana de la población (Guber 2011: 52). Esta metodología se sustenta en que los datos son recogidos a través del contacto y la presencia del/la investigador/a en el entorno socio cultural (Guber, 2011: 52), y permiten identificar las diferencias entre "lo que la gente hace y lo que dice que hace" (Guber 2011: 65).

Es importante analizar las complejidades y limitaciones de este tipo de acercamiento metodológico. La investigación etnográfica es una metodología que permite levantar el interés especialmente académico sobre el conocimiento de realidades comunes o que se viven en el día a día (Quirós, 2018: 122). La práctica política, vista desde sus manifestaciones cotidianas está marcada por interacciones y relaciones interpersonales en diferentes niveles: estatal, partidista, organizativo, barrial, etc. (Quirós 2018: 122).

El análisis de estas interacciones constituye un recurso de inigualable valor político que permite enlazar la acción de votar, el derecho al sufragio, el sentir de la población sobre el proceso electoral, las actividades cotidianas, el uso del espacio público, la construcción del imaginario social, etc. (Quirós 
2018: 135). Es decir, la etnografía política busca analizar "los hechos invisibles de la actividad política" que se manifiestan en el día a día de la población (Quirós 2018: 123).

En la vida cotidiana existen relaciones difíciles de observar, que no se dejan ver fácilmente, pero que resultan claves para entender la lógica de los actores sociales (Auyero 2019: 172). El estudio etnográfico de "lo político" se sustenta en la observación cercana de actores e instituciones políticas en un tiempo y espacio real, a través del cual el/la investigador/a se inserta para identificar "cómo y por qué los actores actúan, piensan y sienten" (Auyero 2019: 174).

La etnografía política permite profundizar en la esfera política de la vida cotidiana (Auyero 2019: 174). Esta metodología trasciende "la superficialidad de las encuestas de opinión" (Auyero 2019: 174), considerando las dimensiones simbólicas de las acciones que requieren de una profundización cualitativa del dato numérico (Auyero 2019: 173).

Como antropóloga interesada en el estudio del proceso electoral, acompañé etnográficamente el accionar del barrio de Solanda en torno a las elecciones seccionales del domingo 24 de marzo de 2019. Ese día se eligieron a nivel nacional un total de 11.069 autoridades: 23 prefectos y viceprefectos (Solanda eligió 1 prefecto y 1 viceprefecto para Pichincha), 221 alcaldes (Solanda eligió 1 alcalde para Quito), 867 concejales urbanos (Solanda eligió 3 concejales urbanos para Quito de la Circunscripción Sur), 438 concejales rurales, 4.089 vocales principales de las juntas parroquiales (estos últimos se eligen solo en contextos urbanos rurales -parroquias- por lo que Solanda no eligió), y 5 miembros del Consejo de Participación Ciudadana y Control Social del Ecuador (Solanda eligió 5 representantes del CPCCS).

Las técnicas de investigación utilizadas para obtener la información fueron: a) revisión bibliográfica sobre otras etnografías del proceso electoral; b) observación participante en los recintos electorales señalados; c) entrevistas a moradores/as del barrio de Solanda; y d) análisis de las entrevistas realizadas por el equipo del Instituto de la Democracia (CNE) a los/as observadores/as internacionales que estuvieron presentes durante las votaciones. El enfoque de esta etnografía es ir más allá de las explicaciones "estadocéntricas" para 
identificar las perspectivas en torno a la democracia, y específicamente a las elecciones, vistas desde la ciudadanía (García 2017: 258).

El alcance de esta investigación da cuenta de las prácticas culturales y las interacciones sociales que se evidencian el día de la votación en el barrio de Solanda; es decir, es un microacercamiento al proceso electoral de carácter nacional, que no pretende analizar los resultados de las votaciones. Pero además se realiza una reflexión epistemológica y metodológica sobre la etnografía y su aplicación en el estudio de "lo político". Es importante señalar que, esta investigación da cuenta de un estudio de caso específico, por lo cual sería interesante realizar otros análisis en más recintos electorales con diferentes características poblacionales que permitan comparar las dinámicas que tienen lugar el día de las elecciones.

El trabajo está dividido en cuatro partes que responden a objetivos específicos. La introducción presenta el problema, las preguntas de investigación, los objetivos, la metodología utilizada y el contenido de cada sección. A continuación se hace una revisión sobre la etnografía y su interés en el estudio de la cultura política, como marco metodológico que ha orientado la presente investigación. En el tercer acápite se describe cómo se viven las elecciones en Ecuador, las acciones y los comportamientos de la ciudadanía que se van volviendo comunes en los comicios electorales. En este contexto, se analiza los sentidos colectivos que genera la población en torno a las elecciones, a pesar de que los "indicadores sobre la situación de la democracia en el país" dan cuenta de otros resultados; se indaga en las interacciones y sus impactos en las estructuras macro sociales, la apropiación del espacio público, las visiones y experiencias desde dentro de los procesos de construcción identitaria, la resignificación de los espacios y la percepción ciudadana in situ. Finalmente, se esbozan algunas conclusiones del estudio.

\section{La etnografía y el estudio de "lo político"}

Existen una multiplicidad de métodos y enfoques a partir de los cuales cada investigador/a elige cómo se estudian las cosas (Della Porta y Keating 2013: 31). En este sentido, uno de los grandes aportes de la Antropología a las Ciencias 
Sociales es su metodología. El trabajo de campo etnográfico, caracterizado por la cercanía que se genera con la población estudiada, permite observar los detalles de las conductas, prácticas, creencias y realidades sociales, en un entorno intercultural (Gledhill 2000: 23-24).

La etnografía puede aportar importantes bases cualitativas para la comprensión de prácticas sociales, culturales, políticas, económicas presentes en la vida cotidiana (Tocancipá 2000: 11). Esta metodología actúa como una lupa sobre los fenómenos políticos, mostrando dimensiones que no son apreciables desde las ópticas macro (García 2017: 250).

A través de la etnografía se busca analizar las normas y los valores que se construyen socialmente mediante la interacción y la significación (Tamayo 2008: 226). Como ha señalado Clifford Geertz, el objeto de la etnografía es definir aquellos signos, gestos, símbolos y sus significados, atendiendo a cuáles se perciben, se producen y se interpretan, y a cómo se perciben, se producen y se interpretan. Así, el dato etnográfico es una explicación analítica sobre aquellas interpretaciones de los/as propios/as actores, y sobre lo que ellos/as piensan, sienten, se imaginan y actúan; es decir, la etnografía implica conocer el proceso de construcción de significados (Tamayo 2008: 227).

En la cotidianidad, muchos fenómenos sociales requieren "agudizar la sensibilidad etnográfica y analítica” porque no se presentan como explícitos a primera vista, y ameritan la observación a profundidad y su análisis (Quirós, 2018: 139). La etnografía es también una excelente manera de prestar atención a acciones que, a primera vista, podrían parecer irrelevantes o simplemente demasiado ordinarias (Wedeen 2010: 261).

Los diferentes estudios de cultura política y la utilización del método etnográfico ${ }^{2}$, para su aproximación, dan cuenta de la aplicabilidad de este enfoque como una herramienta fundamental para el análisis de las percepciones y comportamientos políticos (Tocancipá 1998: 2).

2.- Desde la sociología se la ha conocido como la observación sistemática de la vida cotidiana bajo el nombre de Etnometodología fuertemente trabajado por Harold Garfinkel (Tamayo, 2008: 226). La etnometodología es una perspectiva que revaloriza el proceso de construcción de significados en individuos y grupos sociales (Tamayo, 2008: 226). 
Sin embargo, una revisión sobre el estado de la cuestión en el caso ecuatoriano ha permitido evidenciar la ausencia de investigaciones que aborden el estudio del proceso electoral desde una perspectiva etnográfica. A nivel de otros países, Sergio Tamayo (2008) realizó una etnografía sobre las concentraciones electorales en México, enfocada en los cierres de las campañas, el impacto que tiene la orientación política de la organización ciudadana, el tipo de debate y confrontación de los actores sociales y políticos, la participación de los medios de comunicación y el manejo ideológico de la opinión pública, los repertorios de la movilización y la acción colectiva, entre otros.

Jairo Tocancipá Falla (2000) realizó un recuento etnográfico del proceso vivido por los/as moradores/as de un corregimiento en el sur del departamento del Cauca, durante las votaciones de octubre de 1997 en Colombia. Esta investigación da cuenta del ambiente ciudadano de tensión asociado a la "cultura del terror", el cual se vincula directamente con la actividad política, tanto durante el período pre-electoral (las semanas previas al día de la votación) como en el mismo proceso electoral. En ambos momentos, estos están ligados a las acciones de grupos armados y son alimentados aún más por los medios de comunicación (Tocancipá 2000: 10).

Estos acercamientos metodológicos, que desde la etnografía analizan los comportamientos políticos de la ciudadanía, se enmarcan en una línea definida como la "etnografía política". Autores/as como Donatella della Porta y Michael Keating (2013), Javier Auyero (2012), Lisa Wedeen (2010) y Fernández, Gaztañaga y Quirós (2017) han sido fundamentales para generar reflexiones en este campo.

Javier Auyero señala que hacer etnografía más que un método o una técnica de investigación es una experiencia de vida “... una interacción del etnógrafo con la gente, es un proceso de transformación de la propia persona. Interactúas. Conoces gente.” (Hurtado 2005: 111).

Esta metodología conlleva a que el/la investigador/a se implique durante un periodo de tiempo, observando lo que ocurre, realizando descripciones densas de todo lo que se observa, escuchando lo que se dice, 
preguntando a través de entrevistas, recopilando documentos e información, y recogiendo los datos que más se puedan sobre la temática analizada (García 2017: 251).

No obstante, es necesario señalar que la etnografía suele ser pensada, desde algunos enfoques de la ciencia política, como subordinada frente a métodos de investigación cuantitativos (Hurtado 2005: 111). Muchas veces, el trabajo etnográfico en el marco de la ciencia política tendió a ser reducido a entrevistas de campo y subordinado a modelos teóricos que reducían sus potencialidades (Wedeen 2010: 259). Es decir, algunos enfoques continúan teniendo una preferencia epistémica por datos cuantitativos en detrimento de aquellos de carácter cualitativo, desde los cuales es posible entender tanto la subjetividad de los actores como de la objetividad de las acciones (Auyero 2019: 171).

Patricia García (2017) analiza el repunte que han tenido las investigaciones que utilizan la etnografía como metodología para tratar problemáticas relacionadas con la ciencia política, en un importante esfuerzo interdisciplinario. Desde el estudio del significado y el contexto en el cual se generan los fenómenos políticos es posible mejorar los análisis de la comunicación política y el poder (Wedeen 2010: 258).

Precisamente, otro de los problemas que se ha planteado alrededor de la etnografía como método para la disciplina de la ciencia política es que los elementos cotidianos más "naturales" e "insignificantes" son todos datos para un/a etnógrafo/a, pero estos "detalles" deben ser muy observados para evitar que sean "tediosos o demasiado específicos", impidiendo realizar generalizaciones (Wedeen 2010: 256).

Al respecto, Lisa Wedeen (2010: 257) sostiene que los métodos etnográficos pueden ser utilizados para ayudar a aterrizar las abstracciones y contribuir a obtener generalizaciones en el marco de la ciencia social, desde un conjunto específico de actividades que incluyen la participación en la vida cotidiana de la comunidad, las interacciones ordinarias: reuniones, ceremonias, rituales, elecciones, protestas, chistes, chismes, acontecimientos fortuitos, etc. (Wedeen 2010: 257). La etnografía añade valor a los análisis 
políticos al proporcionar información sobre los/as actores/as vivos/as, y presentar una mirada de la cultura como producción de significados y símbolos que también producen efectos políticos en la población (Wedeen 2010: 261).

Recientemente, se ha renovado el interés por la etnografía en la ciencia política, fuertemente impulsado por J. C. Scott, cuyo enfoque, aunque no sea explícitamente etnográfico, está impulsado por la teoría antropológica (Wedeen 2010: 259). La etnografía, como metodología de análisis, se encuentra en un periodo de renovación y creciente interés en la politología europea y norteamericana (García, 2017: 253). La agenda de investigación sobre cultura política en Estados Unidos, Francia o Latinoamérica se concentra en torno a la etnografía política y sus contribuciones al estudio del poder en los contextos cotidianos o en espacios sociales no institucionales (García 2017: 250).

En el caso específico de la etnografía del proceso electoral se analiza una de las tantas formas de "hacer política", al identificar las prácticas culturales de un proceso que muchas veces se resiste a ser descrito y que constituye una de las principales manifestaciones de la democracia representativa (Tocancipá 2000: 10).

Es necesario pensar en prácticas que usualmente no son pensadas como "políticas" (Fernández, et al. 2017: 292), pero que desde el análisis etnográfico pueden dar cuenta de una construcción social de un espacio ciudadano que se crea a través de prácticas y significados en el marco del proceso electoral (Tamayo 2008: 228). La etnografía de la votación buscó identificar los discursos sociales y políticos que hablan de relaciones empíricas de cambio, poder y conflicto; se utilizó el método etnográfico de observación para describir interacciones y otorgar voz significante a la ciudadanía.

La propuesta es indagar en la política como proceso vivo que se recrea cotidianamente, devolviéndole una perspectiva relacional, holística y dinámica (Fernández, et al. 2017: 278). Desde la etnografía se plantea otra forma de enfocar los fenómenos políticos, a través de la observación participante de diferentes momentos de la vida social (Fernández, et al. 2017: 278).

Esta lógica propia de obtención de información denominada 
"observación participante" (Guber 2011: 51) permite tomar en cuenta las esferas de la realidad sociocultural que no se aprecian a través de las fuentes secundarias o de los mecanismos de sondeo. En la interacción directa es posible que cada gesto y cada acto se articulen y cobren sentido profundo, trascendiendo lo que se observa hacia los significados culturales que tienen para la comunidad estudiada y que se hace evidente en la experiencia vivida: "una cultura se aprende viviéndola" (Guber 2011: 55).

En este proceso de observación participante como lo han señalado Fernández, Gaztañaga, y Quirós (2017: 285): “Son muchos los momentos en los que el trabajo de campo nos enfrenta a la fantasía de que 'lo importante' está sucediendo en otro lado y no exactamente donde estamos". Durante la reconstrucción etnográfica que empezó a las 5:00 y concluyó a las 23:00 horas del día de las votaciones, en múltiples ocasiones pensé que en realidad no ocurría nada "fuera de lo común", diferente de "las acciones cotidianas" vinculadas con el proceso electoral o que difirieran del tiempo ordinario y que, tal vez, habría más elementos que documentar en otros recintos electorales. Por supuesto, al final del análisis, justamente, en las acciones cotidianas del tiempo ordinario durante las elecciones se ha identificado múltiples hallazgos.

La etnografía actúa como una lupa sobre los fenómenos políticos, mostrando dimensiones que no son apreciables desde las ópticas macro (García 2017: 250). De hecho, para Julieta Quirós, los acontecimientos que entran dentro de la esfera de "lo conocido o lo cotidiano" donde se manifiestan las relaciones, percepciones o acciones definidas, son el campo de investigación etnográfica que genera más cuestionamientos que respuestas (Quirós 2018: 138).

Esto da cuenta del carácter emergente e indeterminado de las prácticas, las relaciones y los fenómenos políticos, los cuales son menos racionales de lo que se piensa o de lo que pretenden ser (Fernández, et al. 2017: 279). Si bien éstos se vinculan a elementos estratégicos, acciones instrumentales, cálculos, etc.; también van de la mano con los afectos, los acervos culturales, las tradiciones sociales, etc. (Fernández, et. al 2017: 279).

En este sentido, la investigación indagó alrededor de las prácticas que fueron creadas, reproducidas, transformadas por parte de la ciudadanía 
durante el proceso electoral. Esto permitió, por un lado, analizar los procesos vivos de la política y por otro lado, las dinámicas cotidianas que vinculan la cultura y la política (Fernández, et al. 2017: 281). Pero, además, este trabajo da cuenta de la validez de la etnografía como método para acercarnos al análisis de los fenómenos políticos.

\section{4 de marzo de 2019, día de votación: la apropiación del espacio y la reconstrucción social de lo político}

6:30 de la mañana: rodeando los planteles educativos que son recintos electorales, se escucha los gritos de los/as vendedores/as, quienes han instalado ya algunos puestos con música a todo volumen. Conforme avanza la mañana se puede encontrar de todo: frutas, mollejas, alitas, salchipapas, tostado, huevos de codorniz, hornado, tortillas, menudo, librillo, papas con cuero, chifles, implementos para celular, ropa, camas saltarinas para los/ as niños/as, superhéroes para fotografiarse, etc. (Diario de campo, 24 de marzo de 2019).

Las diferentes acciones ciudadanas que se generan durante el día de las elecciones suelen pasar desapercibidas e incluso son consideradas como efímeras, o como características culturales que aparentemente no se conectan con la política. Sin embargo, es necesario preguntarse qué tan efímeras son esas prácticas, cuando dejan huella en la memoria ciudadana, cambian la percepción del entorno, forman parte del ambiente cotidiano que se repite cada dos años, y le dan una característica particular a este proceso democrático, que lo diferencia de cómo se vive en otros países.

En el Ecuador, el levantamiento etnográfico no puede pasar por alto todo el entramado sociocultural que ocurre alrededor de los recintos electorales y que, tras el análisis de otros estudios de caso, da cuenta de ciertas especificidades en relación con otros países. Al respecto, los/as Observadores/ as Internacionales que vinieron a Ecuador para garantizar la integridad del proceso electoral, realizaron algunas comparaciones y caracterizaciones: 
ETNOGRAFÍA DE LAS ELECCIONES SECCIONALES DE 2019 EN EL ECUADOR. UNA MIRADA ANTROPOLÓGICA SOBRE LA CULTURA POLÍTICA ECUATORIANA EL DÍA DE LA VOTACIÓN.

... he observado elecciones en otros lugares. Las elecciones en Venezuela, por ejemplo, se han convertido en un evento que aterroriza al elector, lo abruma (Entrevista Observadora Internacional Miriam Kornblith. USA. 2019).

En el marco de estas entrevistas y en función de los datos empíricos obtenidos durante la elaboración etnográfica se ha identificado algunas percepciones y comportamientos particulares de la ciudadanía durante el proceso electoral.

\section{La apropiación del espacio público y la reconstrucción social de "lo político"}

\section{Imagen 1.}

Día de la votación: utilización del espacio público por parte de la ciudadanía en los exteriores de los recientes electorales
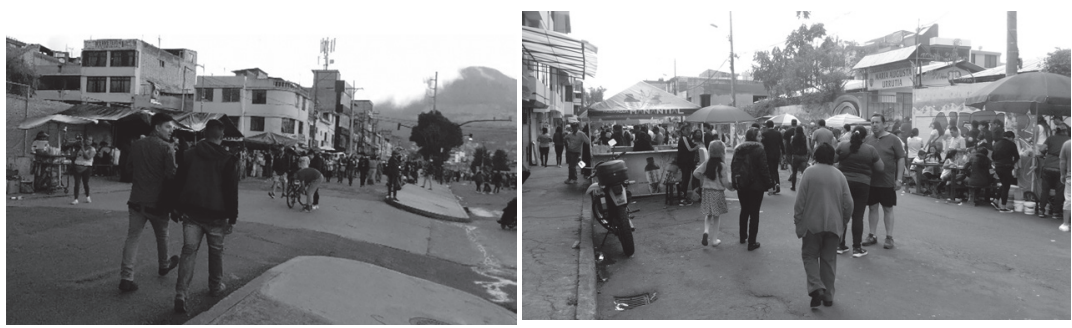

Fotografías tomadas por la autora

Sin lugar a dudas, uno de los elementos más visibles y que más llaman la atención al ingreso de los recintos electorales es la multitud de personas que ofrecen sus servicios y productos, ya sea de venta de alimentos, ropa, 
bebidas, juguetes, emplasticación, fruta cortada, etc. La interacción de la población durante las votaciones, en los recintos electorales y sus alrededores, podría entenderse como una participación ciudadana no institucional que re significa, produce y a la vez transforma el espacio público alrededor de este acto democrático (Tamayo 2008: 213).

El espacio público de la ciudad es el escenario donde la ciudadanía se manifiesta y se construye como identidad política (Tamayo 2008: 214); la reapropiación de esos lugares ordinarios que constituyen la ciudad, es también una acción política (Tamayo 2008: 214).

Desde la mirada ciudadana se ha reinventando la forma de vivir la democracia a través del uso del espacio público, que se expresa como reapropiación, reutilización y revaloración (Tamayo 2008: 213). Una expresión popular y cercana para algunos/as, y para otros/as una manifestación caótica y desordenada:

... en la entrada o a veces al mismo interior del local hacian publicidad para hacer los micados, había una competencia ruidosa y eso también distorsiona. De la puerta para adentro no debería haber nada, solamente entran los que van a realizar el voto, pero aqui era la competencia y sobre todo que eran chiquillos los que hacian la propaganda, entonces ellos con mucha euforia, algunos afuera y otros adentro, o con el aval de la institución educativa o con el aval de la autoridad electoral y eso no puede ser (Entrevista Observador Internacional Ezequiel Chavarry. Perú. 2019).

Durante la observación participante no se registró ningún momento de tensión y por el contrario se vio una gran afluencia de vendedores/as alrededor de los recintos. Las personas que iban a votar por lo general estaban acompañadas, era evidente la presencia de familias e incluso mascotas en las instalaciones. Luego de ejercer su derecho al sufragio, los/as electores/as acudían a comer en las inmediaciones, saludar con los/as vecinos/as, observar las ventas o comer alguna golosina, quedándose un promedio de una hora en el recinto y en las afueras: 
... la gente va a los centros de votación con la familia, los niños, los perros, el ambiente distendido. Los electores y las electoras estaban muy cómodos, muy a gusto de acudir al proceso electoral, y no solamente iban ellos, iba su familia, que realmente era una fiesta de toda la ciudad, de todo el pueblo y había centros de votación llenos de gente, porque además de los electores habian muchas otras personas que simplemente estaban ahi (Entrevista Observador Internacional Miriam Kornblith. USA. 2019).

Me parece que ayer lo que se vivió fue una fiesta, la mayoría de las personas, de manera entusiasta, se lanzaron a las calles a emitir sus votos a ejercer su deber y su derecho ciudadano (Entrevista Observador Internacional Rotsay Rosales. Costa Rica. 2019).

El proceso electoral fue un evento muy familiar, la gente viene a votar con sus hijos, algunos con sus animales, hubo tiendas en las calles, música, fue como una fiesta de la democracian (Entrevista Observador Internacional Régis Dandoy. Bélgica. 2019).

Durante el análisis etnográfico en el barrio de Solanda, se evidenció una serie de acciones desde las que la población reinterpretó y generó otros valores vinculados con la democracia. A través de la vivencia comunitaria del espacio público, la reapropiación de las calles, la participación ciudadana desde las lógicas barriales y locales, entre otros, la "norma" fue revalorizada y se particularizó la manera de vivir el proceso democrático. Desde esta perspectiva, la pluralidad implicó también la interacción con experiencias culturales y políticas, actos y adhesiones a esquemas de pensamiento, marcos de interpretación e imaginarios sociales muy diversos; en definitiva se hizo visibles múltiples valores, bajo los parámetros de libertad, autonomía y responsabilidad, que la ciudadanía asume con respecto a la normas y a las instituciones.

La información obtenida, a través del método etnográfico, presenta otra lectura de los fenómenos sociales, que podría servir para matizar los resultados cuantitativos e incluso la concepción misma del levantamiento cuantitativo, desde la cual no necesariamente se toma cuenta esos otros sentidos que la etnografía revela en este caso particular. 
Por poner un ejemplo, uno de los estudios más importantes de opinión pública sobre el desarrollo de la democracia, la economía y la sociedad en América Latina es producido anualmente por la Corporación Latinobarómetro. Los "Indicadores sobre democracia" se basan en la percepción de los/as ciudadanos/ as; y en el caso ecuatoriano se registró un descenso del apoyo ciudadano de un 64\% en el 2010 a un 50\% en el 2018 (Latinobarómetro 2018: 17).

Estos resultados daban cuenta de tensiones en torno a la democracia: una crisis política en distintos niveles, la incapacidad real del aparato estatal para que la ciudadanía asuma los valores democráticos, en la legitimación de las instituciones establecidas, en la participación en corresponsabilidad con las autoridades y en la garantía de un nivel aceptable de gobernabilidad; dicho en otras palabras: "la democracia perdía apoyo" (Latinobarómetro 2018: 17).

Es decir, estos indicadores reflejaban una "fragmentación y desvinculación política y ciudadana con respecto al régimen y sistema político" (Tamayo 2008: 213). De acuerdo con los resultados del Latinobarómetro, los valores atribuibles a la democracia no eran bien asumidos por la ciudadanía" (Bauman 2002 citado por Tamayo 2008: 221). Estos valores considerados como únicos, dan cuenta de un tipo de "moralidad", y por lo tanto, la negativa de su cumplimiento se traduce en una amenaza a "los principios morales" de la sociedad, que busca la sumisión a la regla y el cumplimiento irrestricto de la norma.

En este sentido, la percepción que se tiene sobre la "crisis de la política" está íntimamente ligada a la percepción ciudadana con respecto a los valores de la democracia y por lo tanto referida también a una crisis de valores (Tamayo 2008: 221). La norma así es un recurso para regular un campo de acción. Pero esa norma se valora y revalora en el transcurso mismo de la acción, y pueden establecerse rupturas, en el sentido de transformar situaciones de acción, redefiniendo así las propias reglas del juego (Tamayo 2008: 227). "No importa lo que se nos ordena hacer, lo que importa es el poder y la legitimidad-respaldada en el poder. De la autoridad que lo ordena" (Bauman 2002 citado por Tamayo 2008: 221).

Bajo estos parámetros, los resultados del Latinobarómetro podrían no verse 
necesariamente como "una crisis de la democracia", sino como un estado natural de las cosas, en donde existe multiplicidad de valores y de formas de percibir y entender el sistema democrático (Tamayo 2008: 221). Y aunque la diversidad de valores en sí misma no garantiza que la sociedad crezca y madure moralmente; en su ausencia los/as individuos/as tienen pocas posibilidades de hacerlo (Bauman 2002 citado por Tamayo 2008: 221).

\section{Gráfico 1.}

Indicadores sobre democracia del 2018

\section{APOYO A LA DEMOCRACIA}

\section{TOTAL POR PAÍS 2018}

$P$. ¿Con cuál de las siguientes frases está Ud. másde acuerdo?

La democracia es preferible a cualquier otra forma de gobierno.

En algunas circunstancias, un gobierno autoritario puede se preferible a un democrático A la gente como uno, nos da lo mismo un régimen democrático. Aquí sólo la democracia es preferible a cualquier forma de gobierno.

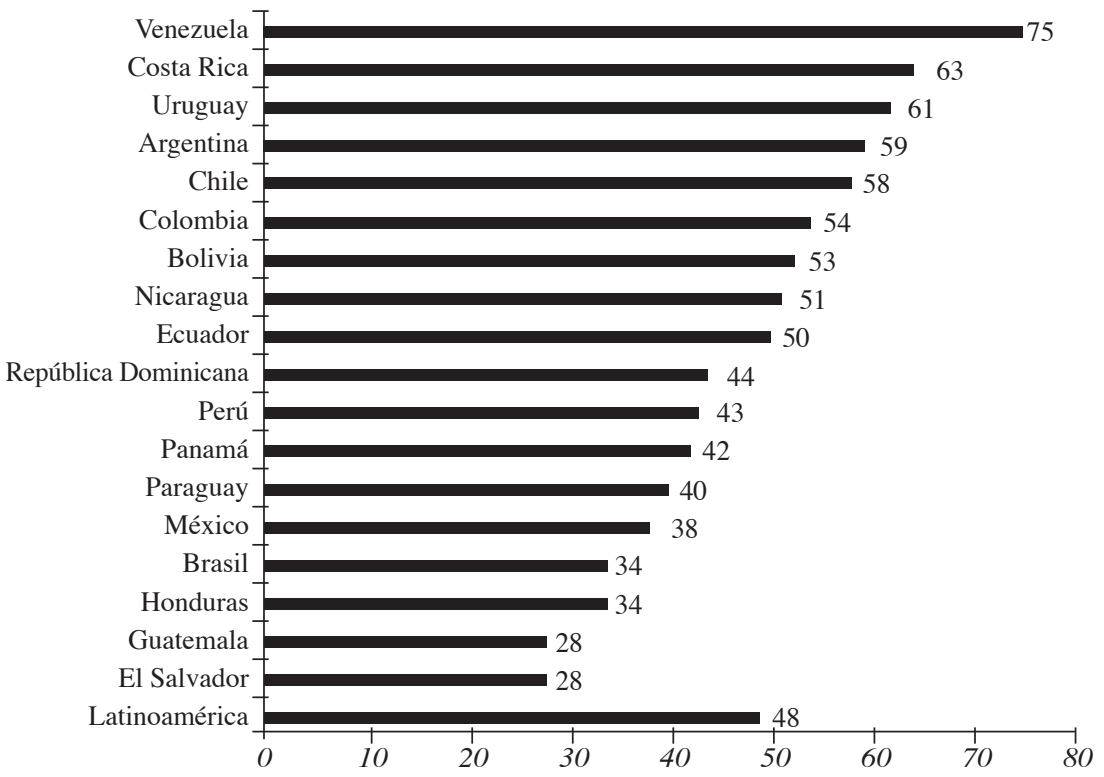

Fuente: Latinobarómetro, 2018. 
Por ello, mirar estas otras formas ciudadanas de vivir el sistema democrático podría resultar ampliamente enriquecedor para la Función Electoral. A pesar del diagnóstico respecto a "la crisis política" que evidencian estudios cuantitativos como el Latinobarómetro, las cuales muestran un desencanto generalizado hacia los gobiernos en toda América Latina (Tamayo 2008: 213), el análisis etnográfico del caso ecuatoriano presenta una nueva mirada sobre la práctica democrática durante el proceso electoral. Los datos etnográficos dan cuenta de un contexto cultural particular e importante de aprovechar en el Ecuador respecto a cómo se viven las elecciones; una nueva faceta, no analizada, sobre la percepción de este ejercicio democrático desde la visión ciudadana:

El día de las elecciones es un día como de fiesta, hay mucha gente yendo y viniendo, es muy alegre ese día, de mucha actividad, según donde uno se vive. La gente se viste diferente para el día de la elección, se viste con la mejor ropita, es bien alegre. (Entrevista JP, comunicación personal, morador del barrio de Solanda, 2019).

Es decir, para la población, el día de las elecciones es un acontecimiento que rompe con el tiempo ordinario, y que se vive con festividad, socialmente. Requiere un cierto grado de preparación, ya sea para acomodar las ventas, para elegir el atuendo, para visitar a las amistades, etc.; es una actividad que se extiende durante todo el día, y que no consiste únicamente en la acción de emitir el voto:

Me pongo una buena ropa, voy caminando y aprovecho encontrando a los amigos, a personas que ya tiempos no las he visto, uno de mis familiares quizá vota en mi misma mesa y ahí aprovecho visitando, ahí nos ponemos a conversar, es un día bonito. Yo no vuelvo a la casa todo el día, aprovecho como un escape (Entrevista MH, comunicación personal, moradora del barrio de Solanda, 2019).

Es importante considerar el hecho empírico de que para el caso del proceso electoral ecuatoriano se ha evidenciado, a grandes rasgos, características 
particulares que han sido distinguidas inclusive por los/as observadores/as internacionales:

Eso me parece un gran capital que tiene Ecuador, de haber convertido la elección en un proceso grato, alegre, aunque es un cliché, es un aspecto positivo que hay que destacar, es una verdadera "fiesta civica" y eso se traduce en otros aspectos. (Entrevista Observadora Internacional Miriam Kornblith. USA. 2019).

Desde estos elementos, es posible evidenciar cómo a través de la comprensión de los procesos sociales y culturales que se generan durante la votación (en la esfera de lo político, lo económico y la vida cotidiana), se puede contribuir a caracterizar el proceso electoral ecuatoriano. La forma en la que la población interactúa en los recintos electorales y en las calles de Quito, da cuenta de "una fiesta electoral", es decir, esta vivencia festiva del día de las elecciones es una característica particular del sistema democrático ecuatoriano, a partir de la cual se puede generar herramientas para el fortalecimiento de la democracia en general.

De todas formas, es importante señalar que el significado de "la fiesta" no necesariamente es homogénea, ni tiene por qué tener la misma intensidad en todos los barrios; llama la atención que, para los/as observadores/as internacionales que fueron entrevistados/as, este sea un adjetivo que describe plenamente lo que ocurre durante el proceso electoral en Ecuador, y que da cuenta además de lo observado durante el levantamiento etnográfico.

Asimismo, se debe puntualizar que en los recintos visitados en el barrio de Solanda, donde se realizó la etnografía, no hubo presencia de la Agencia Metropolitana de Control (AMC,) institución encargada de regular el uso del espacio público o los permisos municipales para el desarrollo de actividades económicas. Sin embargo, en las indagaciones posteriores, respecto a los controles realizados por parte de esta entidad el día domingo 24 de marzo (día de la jornada electoral), se manifestó que 61 funcionarios/as de la AMC distribuidos/as en 30 recintos electorales de la ciudad, ejercieron su potestad sancionadora, controlando el correcto uso del espacio público y las actividades 
económicas que no contaban con los respectivos permisos municipales (Entrevista AJ, comunicación personal, funcionaria de la AMC, 2019).

Es claro que el número de personas encargadas de realizar estos controles (30) es mucho menor que el número total de recintos electorales de la ciudad de Quito, que alcanzaba los 320 establecimientos. Por lo tanto, no resulta extraño que durante la etnografía no se observara su presencia.

Los/as funcionarios/as de la AMC procedieron a recorrer las zonas aledañas a los recintos, verificando que los/as comerciantes cuenten con su "Permiso Único de Comercio Autónomo" (PUCA), mismo que es entregado en las diferentes Administraciones Zonales del Municipio de Quito durante los meses anteriores a las elecciones. En los informes de verificación de la AMC consta que la mayoría de comerciantes contaban con un permiso temporal, autorización obtenida para un período de tiempo corto, en este caso el día de las elecciones (Entrevista AJ, comunicación personal, funcionaria de la AMC, 2019).

Estos operativos suelen ser realizados entre la $\mathrm{AMC}$, la policía metropolitana y en algunos casos la policía nacional. El día de las elecciones, los operativos se iniciaron recorriendo los recintos electorales desde tempranas horas de la mañana, para evitar que los/as comerciantes se instalen: “... cuando hay comerciantes instalados/as se les solicita su permiso, si no lo tienen se solicita se retiren..." (Entrevista DM, comunicación personal, funcionaria de la AMC, 2019).

El resultado de que la mayoría de comerciantes autónomos/as supervisados/ as contaran con su PUCA fue atribuido a la Campaña "Rompe el Círculo", la cual finalizó en el mes de febrero de 2019 y buscaba motivar a los/as comerciantes a regular sus actividades, con el fin de "construir una ciudad ordenada" (Entrevista AJ, comunicación personal, funcionaria de la AMC, 2019).

Por otro lado, llama la atención la movilidad de la gente a lo largo de la ciudad. A pesar de que la sectorización de los recintos electorales fue pensada en función de los lugares de residencia de la población, a partir de cual se escoge a los/as concejales/as de cada circunscripción, y cuyo principio es que las personas votan en sus propios barrios: "Parece un día común y 
corriente porque todo el mundo se traslada de un lado a otro" (Entrevista CA, comunicación personal, moradora barrio de Solanda, 2019).

En las entrevistas, varias personas manifestaron que a pesar de vivir en el barrio de Solanda van a votar en otro sector porque "... es donde he votado siempre, y nunca quise cambiar mi empadronamiento" (Entrevista HA, comunicación personal, moradora barrio de Solanda, 2019). Aquí, es pertinente indicar la importancia de una investigación futura para analizar qué tan generalizado es este comportamiento ciudadano, que además influye directamente en la posibilidad de elegir por determinados concejales/as municipales y no por otros/as, que se eligen en función de la circunscripción de vivienda permanente de los/as empadronados/as:

Siempre he votado en La Tola, desde que me tocó votar en 1978 en el referéndum, porque yo saqué la cédula cuando vivía en La Tola y nunca me cambié (Entrevista HA, comunicación personal, moradora barrio de Solanda, 2019).

Adicionalmente, es esencial mostrar que, en el recinto electoral Colegio María Augusta Urrutia (MAUE), hubo una persona detenida en estado etílico. Según lo establecido en el Art. 123 del Código de la Democracia, al referirse a la "Forma de votación en general", se establece que: "Durante el día de las elecciones, treinta y seis horas antes (36) y doce (12) después, no se permitirá la venta, la distribución o el consumo de bebidas alcohólicas". Es decir, la prohibición de vender, distribuir y consumir bebidas alcohólicas se estableció en estos comicios en todo el Ecuador desde las 12:00 del viernes 22 de marzo, hasta el mediodía del lunes 25 de marzo de 2010, rigiendo de esta manera la denominada Ley Seca ${ }^{3}$.

Esta es una controvertida medida adoptada durante las jornadas electorales, "La aventura de conseguir un trago en Ley seca" (Diario La Hora) señalaba un titular de uno de los principales diarios del país. Según

3.- Esta noticia ha sido publicada originalmente por Diario EL TELÉGRAFO: https://www.eltelegrafo.com. ec/noticias/politica/3/elecciones-silencioelectoral-leyseca y fue visita el 27 de junio de 2019. 
la información identificada, ha sido aplicada por varios Estados de América Latina (excepto Cuba). En México la "Ley seca" se aplica solo en algunos Estados. En Estados Unidos actualmente no existe esta restricción, y Kentucky y Carolina del Sur en 2013 y 2014 respectivamente fueron los últimos dos estados en eliminar su Ley seca electoral. Este tipo de medidas tampoco existen en España ni en los países de la Unión Europea. Y sin embargo, a pesar de la búsqueda y el sondeo realizado, no existen estudios, que den cuenta de la efectividad de la ley seca en la participación electoral.

En el control del cumplimiento de la Ley seca, participaron la Intendencia de Pichincha (50.950 policías desplegados en todo el territorio nacional), los/ as Agentes Metropolitanos de Control y la Agencia Metropolitana de Tránsito; quienes cubrieron el territorio de las 9 administraciones zonales del Distrito Metropolitano ${ }^{4}$. La policía nacional durante esta jornada realizó a nivel nacional 545 citaciones a ciudadanos/as que irrespetaron la Ley: personas que habían expendido o consumido licor, que ingresaron en estado de embriaguez al recinto electoral, pero también aquellos/as que hicieron propaganda dentro o fuera de los establecimientos receptores del voto en días que no estaba autorizado (Entrevista sargento Pablo Tobar, comunicación personal, encargado de la Policía Nacional en el recinto MAUE, 2019).

Estamos esperando que llegue el personal para que procedan a darle la citación. Se nota que la persona es de bajos recursos, estas personas no le toman muy en serio a lo que es la Ley seca. Él se acercó a sufragar, y pues ahi le cogimos (Entrevista sargento Pablo Tobar, comunicación personal, encargado de la Policía Nacional en el recinto MAUE, 2019).

Aquellas personas que infringieron la Ley durante la prohibición deberán pagar una multa del 50\% de una remuneración mensual básica unificada, es decir USD 197 (Entrevista sargento Pablo Tobar, comunicación personal, encargado de la Policía Nacional en el recinto MAUE, 2019). Como ya se ha

4.- Información revisada en https://www.eltelegrafo.com.ec/noticias/judicial/12/policia-detencion-elecciones Consultada el 24 de mayo de 2019. 
señalado antes, sería importante realizar un acercamiento que permita analizar de manera objetiva la efectividad de esta medida.

Hora de votación de la gente

Algunas mesas empezaron el proceso de votación a las 7:30 de la mañana, con una fila bastante larga (15 personas) y muchos/as electores/as esperando desde las 7:00. Esto implica que la conformación de las mesas inició media hora más tarde de lo que estaba planificado. Algunos de los comentarios, identificados en esta espera por parte de los/as votantes, fueron:

Hora ecuatoriana... estamos esperando aqui ya 25 minutos y no atienden, cuando nos ha tocado a nosotros estar en mesa tienes que estar desde las 6 de la mañana, los coordinadores son más bravos y no dan ninguna explicación (Entrevistado ciudadano Junta Electoral Nro. 13, comunicación personal 2019).

Los miembros de las juntas electorales llegan un poco tarde y esto implica que la jornada electoral pueda retrasarse 5-10 minutos sin que esto intervenga en definitiva en el desarrollo del evento electoral (Entrevista Observador Internacional Ramón Villalta. El Salvador. 2019).

A las 9:30 am hubo menos gente que a las 7:30 que empezó el proceso e incluso a esa hora se observaron que varias mesas estaban vacías. Al medio día hubo más afluencia de electores/as, y aunque si se acercó gente a votar durante la lluvia, ya por la tarde la cantidad de personas fue evidentemente menor.

Yo madrugo a votar y de ahí regreso y paso con los vecinos, como tenemos ahi la cancha central, el parque, ese es nuestro pasatiempo, ahi nos vemos (Entrevista RM, comunicación personal, moradora barrio de Solanda, 2019).

El día de la elección yo tomo café y salgo a mi recinto electoral, voy voto, lo más temprano posible, me desocupo y vuelvo (Entrevista JPA, comunicación 
personal, morador barrio de Solanda, 2019).

Algo que me llamó la atención que seguramente es muy particular de Ecuador, es que a partir de las 4 ya no habian ciudadanos que se acercaban a emitir su voto, entonces eso significa que acostumbran a hacerlo a primeras horas (Entrevista Observadora Internacional Lucy Cruz. Bolivia. 2019).

Es interesante observar que muy por la mañana acudieron a votar, en general, personas adultas-mayores; conforme fue transcurriendo el día, los/as votantes fueron cambiando de rango de edad, siendo los más jóvenes los que votaban a últimas horas de la tarde.

Trabajo desplegado en las Juntas receptoras del voto

Otra de las particularidades del proceso, comentada por los/as observadores/as internacionales, tuvo que ver con la organización de las juntas receptoras del voto y la participación de los/as ciudadanos/as en su rol de miembros de juntas:

La dimensión democrática del proceso y en este el papel que cumplieron las juntas receptoras del voto, la actitud respetuosa, cívica muy democrática... no pude observar la más mínima intención de alterar la voluntad de los electores con algún propósito político, distinto al interés de construir transparencia en el proceso y que diera legitimidad en los resultados, es decir, al 100\% podría decir que las personas que intervinieron lo hicieron de manera sistemática, rigurosa apegada a la voluntad de los ciudadanos, durante todo el día y al final en el escrutinio, no me quedo la más mínima duda de que lo hicieron sin estar pensando en posiciones ideológicas o políticas (Entrevista Observador Internacional Fernando Giraldo. Colombia. 2019).

Vi al personal dispuesto a trabajar, lo que es muy importante en las elecciones (Entrevista Observador Internacional Francisco Zaldivar. Panamá. 2019). 
Por otro lado, fue muy visible al interior del recinto, las facilidades y la "atención preferente" que se prestó por parte de quienes estuvieron delegados/as para colaborar allí, tanto funcionarios/as del Consejo Nacional Electoral como la ciudadanía, a personas discapacidades. Aunque la acción parezca de lo más sencilla, es decir, se sacó una silla y una mesa en donde se encontraban tres personas habilitadas como Junta receptora, para que las personas que tuvieran alguna dificultad de movilización pudieran ejercer su voto a la entrada al recinto, este mecanismo fue de gran ayuda en el caso de personas con discapacidad:

Nos hemos acercado, hemos ayudado a que voten y vino incluso ya una persona no vidente y ahi le ayudamos, hemos recibido a 4 personas por el momento (Entrevistada ciudadana Junta Electoral, comunicación personal 2019).

Me llamó mucho la atención lo del voto preferente porque se dio oportunidades a las personas con capacidades disminuidas para que pudieran ejercer su derecho a elegir de una manera muy rápida (Entrevista Observador Internacional Francisco Zaldivar. Panamá. 2019).

Según las apreciaciones de los/as Observadores/as internacionales, esta es otra de las características del proceso electoral ecuatoriano importante de resaltar: la actitud y la forma en que la ciudadanía participa en las Juntas receptoras del voto. Desde su percepción, esta es una característica relevante del proceso ecuatoriano, así como el desarrollo de las acciones tomadas para facilitar la participación democrática de personas con discapacidad.

Una de las cosas que más llama la atención en Ecuador, la que quizá es una de las lecciones para exportar a otros paises, es el compromiso con las personas con discapacidad o que tienen dificultad para ir a las urnas: el voto en casa, el que se haga votaciones el día anterior en las cárceles con aquellos que no han perdido sus derechos políticos, el día de las elecciones con una mesa especial que asiste a las personas que tiene imposibilidad de movilizarse hacia las mesas y tienen una mesa especial de asistencia" (Entrevista Observador Internacional Alejandra Barrios Cabrera. Colombia. 2019). 


\section{El escrutinio}

El recuento de los votos es una parte sustancial del proceso electoral. Para quienes formaron parte de las Juntas receptoras del voto (JRV), independiente de los resultados, el escrutinio se vivió como un momento de alegría previo a la conclusión del trabajo realizado durante todo el día; como el cierre de una jornada laboral exitosa que resultaba indiferente a lo que se definiera en el conteo de las papeletas.

La forma en la que se organizó y realizó el escrutinio dependía de cada JRV, es decir, cada Junta elegía cómo se iban a contar los votos. La Junta Electoral Nro. 13 de mujeres del Colegio María Augusta Urrutia (MAUE) procedió a abrir las cajas donde se receptaron los votos para, en primer lugar, estirar y ordenar en un solo bloque las papeletas y, posteriormente, arreglarlas por partidos en el suelo según la adhesión del/la sufragista. Luego de esta división se contó bloque por bloque para al final contabilizar cuántos votos se había dado a cada partido.

La Junta Electoral Nro. 13 de hombres, del mismo recinto, directamente organizó las papeletas según la preferencia del voto conforme iban siendo desdobladas. Posteriormente, pegaron el acta en la ventana y colocaron directamente el resultado del número de las papeletas para cada partido en el espacio previsto para contabilizar, este proceso terminó más rápido que el seguido por la Junta de mujeres.

\section{Imagen 2.}

Fotografía de las papeletas anuladas tomadas durante el escrutinio
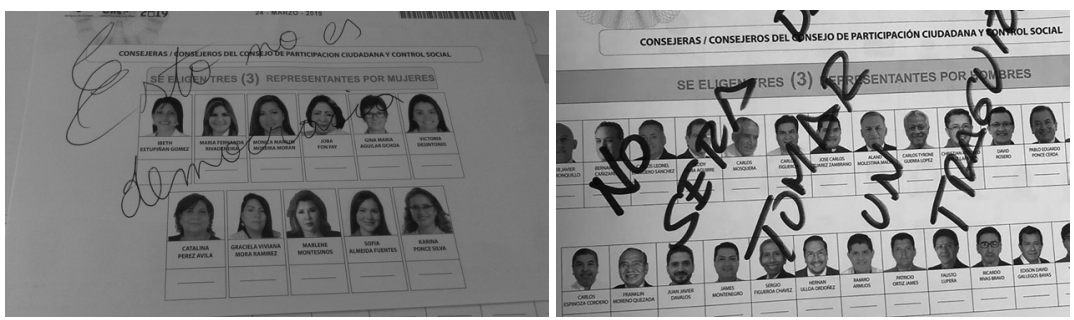

Fuente: fotografías tomadas de internet 
Fueron interesantes las reacciones de los/as integrantes de las JRV frente a los mensajes que venían contenidos en los votos nulos contabilizados: "inútiles", "no se vale falta Manolo Méndez", "Nulo", "Esto no es democracia", "Cómodos", "Si el voto sería importante sería prohibido", "Ninguno sirve", "No cuenten conmigo", "Anulado", "Vagos", "No será de tomar un traguito", entre otros:

Yo como parte de la Junta electoral, por mi mejor que voten nulo, eso es más fácil de contar, y el conteo es lo que más demora (Entrevista Junta receptora del voto Nro. 13, barrio de Solanda, 2019).

Por otro lado, las entrevistas realizadas dan cuentan de la opción del voto nulo como alternativa frente al miedo a equivocarse por parte de la ciudadanía "a dar el voto a los pillos":

Esta es la primera vez que voy a anular porque siempre voté, y siempre me equivoqué y ya no me quiero volver a equivocar otra vez más. (Entrevista DA, comunicación personal, morador del barrio de Solanda, 2019).

... para el poco tiempo que uno ha de vivir ya no quiero, y es mejor vivir en paz que estar renegando que le di el voto a este, que le di el voto al otro" (Entrevista DA, comunicación personal, morador del barrio de Solanda, 2019).

\section{A manera de conclusión}

Resulta innegable la trascendencia e importancia de esas prácticas que se evidencian durante el proceso electoral, cuando dejan huella en la memoria de los/as ciudadanos/as, impactan en las estructuras institucionales, cambian la percepción del entorno, y forman parte ya del urbano cotidiano durante este momento tan determinante para la democracia representativa en el país.

Es fundamental elaborar una hoja de ruta para futuras investigaciones en el campo de la etnografía política; particularmente, respecto a la vivencia 
ciudadana durante el día de las elecciones en más recintos electorales con diferentes características poblacionales, que permitan comparar las dinámicas que se generan y que posibiliten tener un mapeo amplio.

Es oportuno dejar señalada la importancia de investigaciones futuras referente a temáticas que se ha evidenciado en la etnografía como: el empadronamiento real de los/as electores/as y la elección a partir de circunscripciones territoriales, la funcionalidad de la Ley seca y su vigencia en el sistema democrático actual, los mecanismos de escrutinio, el voto nulo y lo que tienen que decir las papeletas electorales, entre otros que se han sugerido a lo largo del artículo.

Estas expresiones y formas de participación, que podrían ser consideradas como efímeras, y que aparentemente no conectan la cultura con la política, impactan en las instituciones y en la forma de vivir la democracia. Esta es una línea de investigación que debe fortalecerse en el caso ecuatoriano, para identificar las particularidades que pueden ser potenciadas desde el mismo Consejo Nacional Electoral, y que deben constituirse en fortalezas sobre la forma en que se vive la democracia en el país.

Por otro lado, hay muchos/as actores/as (funcionarios/as electorales, policía nacional, delegados/as de partidos políticos, militares) que participaron de la jornada electoral y que no han sido considerados en esta investigación, la cual pretende dar cuenta solamente de las dinámicas socio culturales de quienes ejercieron su derecho al sufragio en los recintos electorales del estudio.

En este sentido, respecto a la pregunta en torno a si ¿Es posible aprovechar "La fiesta electoral", que se vive durante las votaciones, para fortalecer el sistema democrático? La respuesta es que la forma particular en la que los/as ecuatorianos/as viven el proceso electoral, puede caracterizar la vivencia democrática desde un punto de vista más humano, pero además optimista para el/la elector/a que no se fundamenta solo en los resultados estadísticos sino en la cotidianidad y en la forma en que la cultura se recrea, adapta y transforma.

Desde la mirada ciudadana se ha reinventando la forma de vivir 
la democracia a través del uso del espacio público, que se expresa como reapropiación, reutilización y revaloración(Tamayo 2008:213). Una expresión popular y cercana para algunos/as, y para otros/as una manifestación caótica y desordenada, pero que en ambos casos se percibe como llena de euforia, alegre, sin tensiones y en el contexto de una afluencia masiva de personas que llegaban acompañadas de sus familias, quienes por lo general, luego de ejercer su derecho al sufragio acudían a comer en los alrededores, saludar con los/as vecinos/as, observar las ventas, etc., en el recinto y sus inmediaciones.

Mirar estas otras formas de acercarse y vivir el sistema democrático podría resultar ampliamente enriquecedor para la Función Electoral, en tanto valora la democracia más allá de los enfoques cuantitativos, para adentrarse en los contextos culturales desde la visión ciudadana recogida a través de los datos etnográficos. Desde ahí se ha podido evidenciar que para la población, la vivencia durante el día de las elecciones rompe con el tiempo ordinario, se vive con festividad y que permite reencontrarse con las amistades y la familia, y tener una vivencia compartida con los/as vecinos/as del barrio. 


\section{Entrevistas}

Entrevista AJ, comunicación personal, funcionaria de la Agencia Metropolitana de Control, 2019.

Entrevista CA, comunicación personal, moradora barrio de Solanda, 2019.

Entrevista DM, comunicación personal, funcionaria de la Agencia Metropolitana de Control, 2019.

Entrevista HA, comunicación personal, moradora barrio de Solanda, 2019.

Entrevista JP, comunicación personal, morador del barrio de Solanda, 2019.

Entrevista MH, comunicación personal, moradora del barrio de Solanda, 2019.

Entrevista JJ, comunicación personal, Miembro de la Policía Nacional, 2019.

Entrevista Sargento Pablo Tobar, comunicación personal, encargado de la Policía Nacional en el recinto MAUE, 2019.

Entrevista Observador Internacional, comunicación personal equipo de la Dirección de Promoción Democrática del IDD, Rotsay Rosales. Costa Rica. 2019.

Entrevista Observador Internacional, comunicación personal equipo de la Dirección de Promoción Democrática del IDD, Regis Dandoy. Bélgica. 2019.

Entrevista Observadora Internacional, comunicación personal equipo de la Dirección de Promoción Democrática del IDD, Miriam Kornblith. USA. 2019. 
ETNOGRAFÍA DE LAS ELECCIONES SECCIONALES DE 2019 EN EL ECUADOR. UNA MIRADA ANTROPOLÓGICA SOBRE LA CULTURA POLÍTICA ECUATORIANA EL DÍA DE LA VOTACIÓN.

\section{Bibliografía}

Auyero, Javier (2019): "Los sinuosos caminos de la etnografía política", Revista colombiana de Antropología, Vol. 55 Nro. 2. Pp. 169-190.

Benton, Allyson Lucinda (2009). "El Efecto de las reglas electorales sobre el comportamiento de la votación indígena en el estado mexicano de Oaxaca”. En Revista Politica y Gobierno. Volumen XVI XVI. Número 1. Pp. 37-69.

Della Porta, D. y M. Keating (2013): Enfoques y metodologías en las ciencias sociales: una perspectiva pluralista, Madrid, Akal.

Dogan, M. (2001): "La ciencia política y las otras ciencias sociales", en R. Goodin y H. D. Klingemann (eds.), Nuevo Manual de Ciencia Política, Madrid, Ediciones Istmo, pp. 150-198.

Eberhardt, María Laura (2015). "Democracias representativas en crisis. Democracia participativa y mecanismos de participación ciudadana como opción". En Araucaria Revista Iberoamericana de Filosofía, Política y Humanidades. Nro. 33. Pp. 83-106.

Fernández Álvarez, María Inés; Julieta Gaztañaga; Julieta Quirós, (2017). "La política como proceso vivo: diálogos etnográficos y un experimento de encuentro conceptual". Revista Mexicana de Ciencias Políticas y Sociales. Universidad Nacional Autónoma de México Nueva España. Año LXII, Nro. 231. Pp. 277-304.

García Espín, Patricia (2017): "Etnografía y Ciencia política: la excepcionalidad del caso español”. Revista Política y Sociedad. Nro. 54. Ediciones complutense. Pág. 249-269.

Gledhill, John (2000). El poder y sus disfraces. Perspectivas antropológicas de las políticas. Serie Universitaria 3. España, Barcelona: Ediciones 
Bellaterra.

Guber, Rosana (2011). La etnografía: método, campo y reflexivididad. 1ra edición. Buenos Aires: Siglo Veintiuno Editores. Pp. 160.

Hurtado, E. (2005): "El oficio de la etnografía política. Dialogo con Javier Auyero", Iconos. Revista de Ciencias Sociales, 22, Mayo, pp. 109-126.

Programa de las Naciones Unidas para el Desarrollo (PNUD) (2004). La democracia en América Latina: hacia una democracia de ciudadanas y ciudadanos. - 2a ed. - Buenos Aires: Aguilar, Altea, Taurus, Alfaguara. Pp. 288.

Quirós, Julieta (2018). "Del intercambio al interconocimiento: la etnografía ante los hechos invisibles del trabajo político". En Íconos Revista de Ciencias Sociales. Nro. 60. Quito: Facultad Latinoamericana de Ciencias Sociales. Pp. 121-142.

Tamayo, Sergio (2008). Tensiones políticas de la modernidad: retos y perspectivas de la democracia contemporánea. Confrontación político y cultura ciudadana. México, D.F.: Universidad Autónoma Metropolitana; Miguel Ángel Porrúa. 262 p.

Tocancipá Falla Jairo (2000). "Etnografía y análisis de una votación”. Revista de la Facultad de Ciencias Humanas y Sociales. Universidad del Cauca. Nro. 3. Pp. 53-69.

Wedeen, L. (2010): "Reflections on ethnographic work in political science", Annual Review of Political Science, 13, pp. 255-272.

\section{Legislación citada}

Constitución de la República del Ecuador. Registro Oficial de Ecuador Nro. 449. 20 de octubre de 2008. 
ETNOGRAFÍA DE LAS ELECCIONES SECCIONALES DE 2019 EN EL ECUADOR. UNA MIRADA ANTROPOLÓGICA SOBRE LA CULTURA POLÍTICA ECUATORIANA EL DÍA DE LA VOTACIÓN.

Ley Orgánica Electoral y de Organizaciones Políticas de la República del Ecuador. Código de la Democracia. Registro Oficial Suplemento 578. 27 de abril de 2009. 